\title{
O ASSÉDIO PROCESSUAL \\ E SUA RELAÇÃO COM O \\ DIREITO DO TRABALHO
}

Antônia Morgana Coelho Ferreira

Pós-graduanda em Direito e Processo do Trabalho pelo Curso Prof. Jorge Hélio. Advogada.

delegada_uniforx@hotmail.com

\section{Saulo Nunes de Carvalho Almeida}

Pós-graduando em Direito do Trabalho, Tributário e Previdenciário pela Faculdade Ateneu.

saulonunes@hotmail.com

Sumário: Introdução. 1) O assédio processual como tipo de assédio moral e suas características. 2) Como identificar o assédio processual. 3) A razoável duração do processo como garantia fundamental. Considerações finais.

Resumo: O presente trabalho visa a estudar as relações trabalhistas sob a óptica judicial, tentando explicar, de forma detalhada, como o assédio processual pode interferir numa relação de trabalho ou de emprego entre empregados ou ex-empregados e seus patrões, e a dificuldade que esse tipo de situação traz ao mercado de trabalho. Sob esse aspecto, serão estudadas as relações entre o assédio processual e a Justiça do Trabalho, a razoável duração do processo, os princípios inerentes a essa situação jurídica, bem como será desenvolvido um estudo sobre como esse assédio diferenciado macula a ordem jurídica, imposta pela Constituição Federal de 1988, ao infringir princípios fundamentais dessa mesma ordem, tais como a dignidade da pessoa humana, como princípio fundamental e a busca do pleno emprego, como princípio inerente à ordem social vigente. $O$ presente estudo visa também inserir o assédio processual dentro do assédio moral, possibilitando o conhecimento desse tipo de assédio diferenciado e como as relações são prejudicadas quando alguns dos litigantes fazem um uso errado desses institutos. Palavras-chave: Assédio processual. Princípios fundamentais. Razoável duração do processo.

\section{INTRODUÇÃo}

O assédio processual é um instituto jurídico ainda pouco explorado pela doutrina, tendo sido citado pela primeira vez por uma juíza de São Paulo, em um 
processo tramitando na $63^{\mathrm{a}}$ Vara do Trabalho. Na ocasião a magistrada determinou a condenação do reclamado por assédio processual, além de aplicar a multa por litigância de má-fé, causando alvoroço e provocando uma discussão jurídica sobre a condenação.

Nesse sentido, quando o reclamado se viu obrigado a pagar tanto a multa por litigância de má-fé, como a indenização por assédio processual, encontrou-se aparato jurídico para analisar o instituto como sendo uma ramificação do assédio moral, estritamente ligado ao processo e seu razoável andamento, enquanto garantia constitucional.

De sorte que, assédio processual e litigância de má-fé são dois institutos diferentes, mas que não deixam de ter características que os aproximam, e que muitas vezes até os confundem.

Desta forma, correto o enquadramento do instituto analisado como sendo um dos ramos do assédio moral, visto que a adequação com uma forma grotesca de assédio está na própria definição do assédio processual, quando este visa claramente prejudicar a parte vencedora, impondo a ela condições humilhantes e muitas vezes infundadas.

$\mathrm{O}$ assédio processual, nesse passo, emerge na jurisprudência como sendo uma ramificação do assédio moral, que será capaz de colocar em ordem as condenações que não se cumprem nesse país além de trazer à tona uma discussão positiva sobre a real celeridade existente.

\section{ASSÉDIO PROCESSUAL COMO TIPO DE ASSÉDIO MORAL E SUAS CARACTERÍSTICAS}

A proteção contra o assédio moral surgiu na década de 1980, com o advento da Constituição da República Federativa do Brasil, de 1988, onde determina, em seu art. 50: "é assegurado o direito de resposta, proporcional ao agravo, além da indenização por dano material, moral ou à imagem".

Desse modo, surge para a parte um valioso instrumento de defesa contra os abusos cometidos pela parte adversa, para se ver livre de pagar um direito assegurado, além de proteger a parte vencedora de sofrer abusos, no que concerne ao uso do seu direito.

Ingressar em juízo, atualmente, é mais fácil que antigamente. Em contrapartida, aumentaram as situações em que as pessoas levam anos para finalmente usufruírem os direitos declarados pela tutela jurisdicional.

Todos fazem um mal uso do processo, objetivando o não cumprimento da prestação jurisdicional. 
Miguel Reale acrescenta que o dano moral, em sua feição subjetiva, protege os direitos de personalidade, como a intimidade, a vida privada, a honra, a liberdade de pensamento, do uso do corpo, tudo o que envolve a faceta interna do indivíduo, sua visão de si para si, tudo o que pode gerar sentimento de dor, de abalo psíquico na pessoa, já que são direitos que envolvem 'o homem consigo mesmo'. (SILVESTRIN, 2003, on line)

Na visão acima, o dano moral envolve situações que abalam psiquicamente uma pessoa, que causam dor e sofrimento. Afirma-se com isso que, assediar moralmente alguém, provocará dores e danos, muitas vezes permanentes.

Como imaginar então, que essa dor permanente será aliviada com algo menos do que a satisfação pessoal de ver seus direitos respeitados?

Qualquer cidadão normal, que acorda cedo para trabalhar, sustenta uma família inteira e ainda tem que encontrar tempo para o lazer, sofre quando se vê obrigado a ingressar com uma ação judicial e esperar anos para ter sua satisfação. Esse sofrimento é resultante não somente da morosidade da justiça, mas, sobretudo, pelo fato de ela permitir que aconteçam situações processuais vexatórias a seus protegidos.

Partindo desse pressuposto constitucional, as partes que ingressam em juízo em busca de uma solução para o seu conflito, estão relativamente protegidas contra a ocorrência de qualquer tipo de dano, sendo assegurado a todas indenização caso sofram assédio durante o período em que permanecerem como partes em uma ação judicial.

A proteção apenas relativa abre um leque extenso de possibilidades de subterfúgios, onde o mais forte economicamente acaba tendo razão, ou encontrando meios de burlar o direito da outra parte, apenas para se ver livre de cumprir uma obrigação.

Dentre os muitos ramos que o assédio moral possui, um está atualmente em evidência: o assédio processual. Não por ser algo extraordinário ou de difícil compreensão, mas pelas próprias especificidades que possui.

Infelizmente, a justiça brasileira ainda é pouco célere, tendo o Direito do Trabalho a árdua missão de conseguir uma razoável rapidez quando da apreciação de seus julgados, não permitindo que se use de artifícios protelatórios para atrasar o andamento do feito. Não obtém, contudo, em muitos dos casos, o seu intento, mas tem a clara intenção de tentar acelerar ao máximo a resolução da lide.

Desse modo, o juiz tem em mãos um poderoso instrumento para combater o uso de recursos protelatórios, usados para se evitar, o quanto possível, que o reclamante obtenha o que lhe é devido.

Trata-se de um ramo específico do assédio moral, relacionado intimamente com o processo e seu razoável andamento, sendo certo, que a vontade de todos aqueles que procuram o judiciário para a resolução de alguma controvérsia, querem 
ver seu direito satisfeito e caso essa satisfação não seja alcançada, que tenha sido dado às partes todo o aparato jurídico para que tenham suas exigências examinadas.

Desta forma, trata-se de um meio jurídico hábil a que se garanta a plena satisfação do direito perseguido, sem que uma parte se veja prejudicada por outra, quando esta interpõe recursos meramente protelatórios, com o claro intuito de atrasar a satisfação pretendida.

O assédio processual tornou-se conhecido quando a juíza Mylena Pereira Ramos condenou uma grande instituição bancária a pagar indenização devido ao assédio, bem como aplicou a multa por litigância de má-fé, fazendo clara diferenciação entre os dois. Nessa ação, o reclamante era sempre obrigado a interpor ações para requerer seus direitos, já assegurados por uma sentença judicial, deixando claro que o banco sempre descumpria a ordem judicial.

Durante muitos anos o único remédio jurídico eficaz contra os recursos protelatórios era a litigância de má-fé, prevista no art. 17, do CPC, porém, com advento do assédio processual, ficou claro que existem outros meios eficazes de combate ao atraso processual.

Dessa forma, dentro desse contexto de busca por uma definição real do que significa o assédio moral, onde se enquadra o assédio processual, verificou-se o pensamento de Luiz Salvador (apud SILVESTRIN, 2003, on line):

[....] O assédio moral é caracterizado pela degradação deliberada das condições de trabalho onde prevalecem atitudes e condutas negativas dos chefes em relação a seus subordinados, constituindo uma experiência subjetiva que acarreta prejuízos práticos e emocionais para o trabalhador e a organização. A vítima escolhida é isolada do grupo sem explicações, passando a ser hostilizada, ridicularizada, inferiorizada, culpabilizada e desacreditada diante dos pares. Assediar é submeter pois alguém, sem trégua, a pequenos ataques repetidos com insistência, cujos atos tem significado e deixam na vítima o sentimento de ter sido maltratada, desprezada, humilhada, rejeitada. É uma questão de intencionalidade. A forma de agir do perverso é desestabilizando e explorando psicologicamente a vítima. O comportamento perverso é abusivo, é uma atitude de incivilidade. Os efeitos do assédio tem estilo especifico que deve ser diferenciado do estresse, da pressão, dos conflitos velados e dos desentendimentos.

Quando o assédio ocorre é sempre precedido da dominação psicológica do agressor e da submissão forçada da vítima.

A pessoa tomada como alvo percebe a má intenção de que é objeto, ela é ferida em seu amor próprio, sente-se atingida em sua dignidade e sente a perda súbita da autoconfiança. É um traumatismo que pode gerar uma depressão por esgotamento e doenças psicossomáticas.

Nossos sistemas educativos nos ensinaram a temer os conflitos e por isso a vitima pondera as humilhações.

É uma relação de dominante-dominado na qual aquele que comanda o jogo procura submeter o outro até que ele perca a identidade e fica cada vez mais difícil se defender. 
A recusa de reconhecer as diferenças pessoais também é um meio de desestabilizar uma pessoa pois ao formatar os indivíduos é mais fácil controlálos e impor a lógica do grupo.

O indivíduo que é vítima perde a confiança e tem a sensação de não saber nada.No trabalho as pessoas são desestabilizadas colocando em evidencia seus erros, colocando objetivos impossíveis de serem realizados e tarefas absurdas ou inúteis.

Não fornecer a uma pessoa conscienciosa os meio de trabalhar é uma maneira eficaz, se for feito sutilmente, de lhe passar a imagem que ela é uma nulidade e que é incompetente, abalar sem que o outro compreenda o que aconteceu. A violência começa pela negação da própria existência do outro. (grifou-se)

Diante disso, o assédio processual se apresenta como uma forma de prejuízo para uma das partes, quando ela se vê despida de aparatos jurídicos para combater os abusos perpetrados por aqueles que têm obrigação de fazer um bom uso do processo e não de torná-lo um calhamaço de papel sem sentido algum.

Nesse caso, não há que se falar em inserir o assédio processual dentro da litigância de má-fé, considerando que os dois são diferentes, e sim classificá-lo, tal como se apresenta, dentro do assédio moral, ligado intimamente ao processo, quando há um claro prejuízo ao andamento razoável do processo, direito esse albergado pela constituição, erigido á categoria de garantia fundamental.

$\mathrm{O}$ instituto ora em exame apresenta características que o distingue dos outros ramos do assédio moral, bem como da litigância de má-fé, mostrando que, dentro de suas particularidades, cada um deles têm a função de não prejudicar as partes e assegurar a solução correta e justa da lide.

Desse modo, o assédio processual apresenta-se como um meio de impedir que se instale o caos na Justiça Brasileira, já tão mitigada pelo errôneo uso de todos os aparatos que oferece para que se consiga a plena realização da justiça e que se encontre a verdade real.

\section{COMO IDENTIFICAR O ASSÉDIO PROCESSUAL}

Por se tratar de um novo tipo de assédio, torna-se uma tarefa complicada a sua classificação. Como um ramo de assédio moral abre diversas hipóteses de identificá-lo, porém, tem-se uma especificação que o coloca como um ramo de assédio moral: a perseguição ao empregado relacionada ao processo e os meios inescrupulosos de que as pessoas fazem uso para se eximir de pagar suas obrigações.

Mas problemas logo se apresentaram: como qualificar corretamente o novo instituto? Seria ele um tipo de litigância de má-fé, ou um novo tipo de assédio moral, ou um instituto autônomo? 
Classificar um instituto é uma tarefa complicada, vez que é preciso que se tenha uma visão ampla e irrestrita de todos os seus componentes. Sendo assim, considerando que na ciência nada é completamente certo e inatacável, a jurisprudência, nas palavras primorosas da Juíza Mylena Pereira Ramos, nos autos do processo $n^{\circ}$ 02784200406302004, da $63^{\mathrm{a}}$ Vara do Trabalho de São Paulo, no qual figuram como partes - Autor: Carlos de Abreu, Réu: Banco Itaú S.A, buscou a melhor definição para o assédio processual:

[....] procrastinação por uma das partes no andamento do processo, em qualquer uma de suas fases negando-se a cumprir decisões judiciais, amparando-se ou não em norma processual, para interpor recursos, agravos, embargos, requerimentos de provas, petições despropositadas procedendo de modo temerário e provocando incidentes manifestamente infundados tudo objetivando obstaculizar a entrega da prestação jurisdicional à parte contrária [....].

Dessa forma, acabava de ser inserido no Ordenamento Jurídico Brasileiro um novo instituto que guarda certas semelhanças com a já conhecida e bastante divulgada litigância de má-fé. Nesse contexto, como qualificá-lo? Seria ele um tipo de litigância de má-fé?

Como já exposto anteriormente, ele está inserido dentro do assédio moral, como ramo autônomo, tendo características semelhantes à litigância. Em contrapartida, tem características muito particulares, que o colocam como uma "modalidade de assédio moral, mas restrita a atuação da parte em juízo" (PAROSKI, 2008, p. 36).

Situações já exploradas pela jurisprudência dão conta de que o assédio processual é uma categoria ainda pouco explorada, mas já muito utilizada pelos juízes em condenações que impõem à parte uma obrigação de fazer com base no uso injustificado do aparato jurídico, tais como o uso de embargos declaratórios meramente protelatórios, tema dos próximos capítulos.

Tarefa árdua, que muitas vezes leva realmente ao erro, considerando sua semelhança com a litigância de má-fé. No entanto, por serem condutas estritamente processuais, aquelas que levam a esse tipo de assédio, além de essas condutas serem formas de humilhar e ofender os litigantes, torna-se mais fácil compreender que o assédio processual resvala em condutas que prejudicam moralmente a parte que já ganhou a ação.

Trata-se de uma forma amarga de resolução de conflitos, quando a parte se vê obrigada a interpor recursos com o fito de evitar o atraso na satisfação da sua prestação, quando é exatamente a interposição de recursos que atrapalha o correto andamento do processo. 
Para Francisco Xavier de Sousa Filho (2007, on line), o assédio moral é um meio criminoso de obtenção de resultados, senão vejamos:

Surge então o assédio moral no processo quando a lesão de direito ocorreu, mas, sem motivo justo nenhum para contestação, a parte nega a procedência inarredável da ação. No propósito de arranjar meios condenáveis em adiar o final da ação, usando de artifício da malandragem e criminoso para lograr ou levar ao erro o julgador, como tem acontecido, o ato ilícito aparece.

\section{Nas palavras de Roberto Benavente Cordeiro (2005, on line):}

Inegável o prejuízo que a injustificada morosidade no andamento processual causa ao titular do direito a ser reconhecido, mormente em âmbito juslaboral, em que o cabimento de títulos de natureza alimentar, asseguradores do mínimo necessário à subsistência do ser humano é discutido. $\mathrm{O}$ empregado depende essencialmente desse núcleo mínimo de direitos para sobreviver. Uma vez não concedidas tais verbas ao longo do pacto laboral, resta claramente configurada afronta à dignidade humana do obreiro, o que por si só, resulta em abalo moral.

Mário Vasni Paroski (2008, p. 38), continua sua definição de assédio processual, e muitas vezes o aproxima do conceito de litigância, mas deixa claro que os dois são diferentes:

Entende-se, em linhas gerais, que assédio desta natureza consiste no exercício abusivo de faculdades processuais, da própria garantia da ampla defesa e do contraditório, pois, a atuação da parte não tem a finalidade de fazer prevalecer um direito que se acredita existente, apesar da dificuldade em demonstrá-lo em juízo, nem se cuida de construção de teses sobre assuntos em relação aos quais reina discórdia nos tribunais, a exemplo de uma matéria de direito, de interpretação jurídica, complexa e de alta indagação.

Nada disso. O verdadeiro propósito do litigante é dissimulado, pois, sob a aparência de exercício regular das faculdades processuais, deseja um resultado ilícito ou reprovável moral e eticamente, procrastinando a tramitação dos feitos e causando prejuízos à parte que tem razão, a quem se destina a tutela jurisdicional, além de colaborar para a morosidade processual, aumentando a carga de trabalho dos órgãos judiciários e consumindo recursos públicos para a prática de atos processuais que, sabidamente, jamais produzirão os efeitos (supostamente lícitos) desejados pelo litigante assediador.

Por esses aspectos, o assédio, além de prejudicar diretamente as partes, prejudica a própria Justiça Brasileira, quando atrasa a correta solução da lide, prejudica o andamento processual, permite a interposição de recursos e mais recursos com o propósito de atrapalhar a parte em suas alegações e, finalmente, não permite à parte vencedora a plena realização de seus propósitos, nem aos juízes que encontrem para o caso a verdade real. 
O que se pretende é que a Justiça seja ágil. Tal agilidade apenas será encontrada quando se fizer um uso eficaz de todo o aparato jurídico à disposição e não fazer uso desse aparato de modo temerário e abusivo, causando inúmeros e muitas vezes irremediáveis prejuízos, não apenas às partes, mas à toda a população.

Dessa forma, quando o judiciário brasileiro impõe uma condenação, se espera que ela seja efetivamente cumprida e que, assim, se encontre a plena satisfação e se faça a tão sonhada "justiça".

\section{A RAZOÁVEL dURAÇÃo DO PROCESSO COMO GARANTIA FUNDAMENTAL}

A Emenda Constitucional 45/2004, acrescentou ao art. $5^{\circ}$, da Constituição da República Federativa do Brasil de 1988, o inciso LXXVIII, erigindo à categoria de direito fundamental a razoável duração do processo.

Entretanto, muito antes da emenda em questão ser aprovada, o próprio artigo quinto já possuía em seu texto, incisos fazendo referência a que o Estado tem obrigação de prestar a função jurisdicional de forma rápida e eficiente, consoante o que apregoam os princípios da inafastabilidade do poder jurisdicional (art. $5^{\circ}$, XXXV); do devido processo legal (art. $5^{\circ}$, LIV); do contraditório e da ampla defesa $\left(\operatorname{art.} 5^{\circ}, \mathrm{LV}\right)$, todos asseguradores de uma prestação jurisdicional eficiente.

Por força de tais princípios, já era garantido ao cidadão o direito a um processo que lhe garantisse usufruir de todas as regalias, além de lhe conferir o direito a uma prestação eficiente, como bem apregoa o art. 37, da CF, e célere, corolário das diversas modificações impingidas pela Emenda Constitucional 45/2004.

No entanto, muito antes da própria Constituição de 1988, a Declaração Universal dos Direitos Humanos, adotada e proclamada pela resolução 217 A (III) da Assembléia Geral das Nações Unidas em 10 de dezembro de 1948, já previa em seu art. X:

Toda pessoa tem direito, em plena igualdade, a uma audiência justa e pública por parte de um tribunal independente e imparcial, para decidir de seus direitos e deveres ou do fundamento de qualquer acusação criminal contra ele.

Da leitura vê-se que a declaração dos direitos humanos já havia se preocupado com a garantia de uma assistência judiciária eficiente, sendo assegurado a todos o direito à assistência por um tribunal imparcial, na defesa de seus interesse e garantias fundamentais.

Pode-se observar a preocupação do mundo com as causas sociais, visto que hoje, não se admite, principalmente em um estado democrático de direito, como o é a República Federativa do Brasil, que não sejam respeitadas as liberdades e garantias fundamentais. 
Já em 1950, a Convenção Européia para a Proteção dos Direitos Humanos e Liberdades Fundamentais, estabeleceu em seu art. $6^{\circ}, \S 1^{\circ}$, o seguinte:

\begin{abstract}
Qualquer pessoa tem direito a que a sua causa seja examinada, equitativa e publicamente, num prazo razoável por um tribunal independente e imparcial, estabelecido pela lei, o qual decidirá, quer sobre a determinação dos seus direitos e obrigações de carácter civil, quer sobre o fundamento de qualquer acusação em matéria penal dirigida contra ela. O julgamento deve ser público, mas o acesso à sala de audiências pode ser proibido à imprensa ou ao público durante $\mathrm{a}$ totalidade ou parte do processo, quando a bem da moralidade, da ordem pública ou da segurança nacional numa sociedade democrática, quando os interesses de menores ou a protecção da vida privada das partes no processo o exigirem, ou, na medida julgada estritamente necessária pelo tribunal, quando, em circunstâncias especiais, a publicidade pudesse ser prejudicial para os interesses da justiça.
\end{abstract}

Nesse sentido, a conhecida convenção albergou em seu texto que a causa deve ser examinada em tempo razoável, explicitando que as causas examinadas se constituem em uma obrigação do Estado Democrático de Direito e em um direito do cidadão de se ver assistido sendo permitido a ele gozar de suas garantias, em tempo hábil.

Também se infere do excerto acima, que o acesso à justiça deve ser apregoado em todas as situações, sem que os magistrados e todos aqueles encarregados de analisar a situação no caso concreto, dentro dos ditames da lei, se exima de prestar essa função eficientemente.

Continuando a análise histórica da razoável duração do processo, em 26.05.1992, o Congresso Nacional, mediante o Decreto 27, aprovou a Convenção Americana sobre os Direitos Humanos, denominada de Pacto de São José da Costa Rica. Com o Decreto 678, de 09.11.1992, a convenção foi promulgada, obedecendo o disposto no art. $5^{\circ}, \S 3^{\circ}$, da Constituição Federal, o qual se manifesta também nesse sentido, senão vejamos:

Artigo $8^{\circ}$ - Garantias judiciais

1. Toda pessoa terá o direito de ser ouvida, com as devidas garantias e dentro de um prazo razoável, por um juiz ou Tribunal competente, independente e imparcial, estabelecido anteriormente por lei, na apuração de qualquer acusação penal formulada contra ela, ou na determinação de seus direitos e obrigações de caráter civil, trabalhista, fiscal ou de qualquer outra natureza.

Pode-se observar, então, que a garantia da razoável duração do processo já estava inserida dentro do Ordenamento Jurídico brasileiro antes da Constituição de 1988. Antes mesmo da emenda 45/2004, que reformou o judiciário, os litigantes já gozavam de certas garantias constitucionais, insculpidas nos princípios anteriormente citados. 
Algumas outras constituições no mundo, tais como a da Espanha, da Itália, de Portugal e do Canadá, já traziam em seu texto referências a que o processo deveria ser célere, justo e deveria ser deslindado em tempo razoável, a que se garantisse, inclusive que o direito não perecesse em razão do tempo demasiadamente longo a que se desse resultado a uma controvérsia.

Por fim, com o intuito de tornar mais claro o advento de tal princípio dentro do Ordenamento Jurídico, foi que a Emenda Constitucional $n^{\circ} 45 / 2004$, trouxe ao texto do art. $5^{\circ}$, o inciso LXXVIII, o qual estabelece que:

Art. $5^{\circ}$ Todos são iguais perante a lei, sem distinção de qualquer natureza, garantindo-se aos brasileiros e aos estrangeiros residentes no País a inviolabilidade do direito à vida, à liberdade, à igualdade, à segurança e à propriedade, nos termos seguintes:

$[\ldots]$;

LXXVIII - a todos, no âmbito judicial e administrativo, são assegurados a razoável duração do processo e os meios que garantam a celeridade de sua tramitação. (grifou-se).

Pela leitura, depreende-se que a razoável duração do processo é uma garantia constitucional, e como tal deve ser respeitada e, principalmente, utilizada, na solução das controvérsias e problemas que se apresentam todos os dias. Carecendo de uma solução, portanto, o processo deve ter uma duração razoável, que permita à parte usufruir de seus direitos e não tenha obstada a sua satisfação pessoal ao deslinde de cada feito.

Dentre desse contexto, se quer que o judiciário cumpra seu papel de forma eficiente, célere e com respeito à dignidade da pessoa humana, considerando que o ser humano não pode esperar anos para ver seus direitos serem observados e respeitados, como tem acontecido.

Dessa forma, considerando que o direito à razoável duração do processo está consagrado na Lei Magna como fundamental, o que se pode esperar é que o judiciário obedeça o que a Lex Fundamentalis apregoa, no sentido de tornar a prestação do estado de direito algo eficiente e célere.

\subsection{A RELAÇÃo do PRINCÍPIO DA DURAÇÃo RAZOÁVEL DO PROCESSO COM O ASSÉDIO PROCESSUAL}

Uma das mais importantes mudanças dos últimos anos, impingir ao processo uma característica de celeridade fez com que muitos litigantes fossem condenados pelo mal uso dos institutos jurídicos além de fazer surgir novos meios de combate à morosidade da justiça. 
A sua importância [do art. $5^{\circ}, \mathrm{XXXV}$, da CF/88], dentro da estrutura do Estado Democrático de Direito, é de fácil assimilação. É sabido que o Estado, após proibir a autotutela, assumiu o monopólio da jurisdição. Como contrapartida dessa proibição, conferiu aos particulares o direito de ação, até bem pouco tempo compreendido como direito à solução do mérito.

A concepção de direito de ação como direito a sentença de mérito não poderia ter vida muito longa, uma vez que o julgamento do mérito somente tem importância - como deveria ser óbvio - se o direito material envolvido no litígio for realizado - além de reconhecido pelo Estado-Juiz. Nesse sentido, o direito à sentença deve ser visto como direito ao provimento e aos meios executivos capazes de dar efetividade ao direito substancial, o que significa direito à efetividade em sentido estrito.

Mas, não há como esquecer, quando se pensa no direito à efetividade em sentido lato, de que a tutela jurisdicional deve ser tempestiva e, em alguns casos, ter a possibilidade de ser preventiva. Antigamente, questionava-se sobre a existência de direito constitucional à tutela preventiva. Dizia-se, simplesmente, que o direito de ir ao Poder Judiciário não incluía o direito à 'liminar', desde que o jurisdicionado pudesse afirmar lesão ao direito e vê-la apreciada pelo juiz. Atualmente, diante da inclusão da locução ‘ameaça a direito' na verbalização do denominado princípio da inafastabilidade, não há mais qualquer dúvida sobre o direito à tutela jurisdicional capaz de impedir a violação do direito.

$\mathrm{Na}$ verdade, essa conclusão é pouco mais do que óbvia, especialmente em face dos direitos ditos invioláveis, alguns erigidos a direitos fundamentais pela própria Constituição.

Em outros termos, o direito à tutela inibitória está contido na própria estrutura da norma que institui algumas espécies de direitos, pois não há como conceber a existência de norma que outorgue direito inviolável sem conferir direito à inibição do ilícito.

Como se vê, o direito à inibição do ilícito está no plano do direito material, pois decorre da sanção que compõe a própria norma que outorga o direito, e não na esfera do direito processual. O processo é somente técnica para a prestação da tutela inibitória, pois essa última já é garantida pelo direito material. Porém, se o processo, diante da natureza de algumas situações de direito substancial, não estiver disposto de modo a viabilizar a outorga da tutela inibitória àquele que a ela tem direito, certamente estará negando o direito fundamental à tutela jurisdicional preventiva.

Importa, ainda, o direito à tempestividade da tutela jurisdicional. $\mathrm{O}$ direito à tempestividade não só tem a ver com a tutela antecipatória, como também com a compreensão da duração do processo de acordo com o uso racional do tempo processual por parte do réu e do juiz. (MARINONE, 2004 apud BASTOS, 2006, on line).

Como se depreende do excerto acima e das informações anteriormente citadas, não se trata especificamente de uma inovação, mas de uma reafirmação de uma regra que já existia, mas que não era devidamente respeitada pelos operadores do direito. Essa norma traz em si um comando explícito de que o processo deve 
ter uma duração que propicie ao cidadão querer ingressar na justiça para ter seus direitos assegurados, tudo dentro de um prazo razoável.

Vale lembrar que essa garantia deriva diretamente do devido processo legal, já expresso no texto constitucional (art. $\left.5^{\circ}, \mathrm{LIV}\right)$, o que já garantia aos litigantes que a tutela jurisdicional fosse alcançada dentro de um lapso de tempo razoável.

$\mathrm{O}$ assédio processual, conhecido há pouco tempo do grande público, se mostra como um entrave a que se alcance esse direito, sendo um dos meios mais utilizados pelos operadores do direito na busca por prejuízos e morosidade do processo. Configura um desrespeito à norma constitucional do devido processo legal e à sua mais nova ramificação: o direito a um processo de duração razoável.

No que concerne ao assédio processual, ele se mostra como um meio abusivo, onde a parte que vence, muitas vezes em um espaço até razoável de tempo, demora o dobro desse período para ver realmente seus direitos respeitados e garantidos, já que a parte perdedora tenta de todas as formas impedir que a parte vencedora goze de seus direitos.

O litigante vencedor é obrigado a esperar muitos anos para se ver ressarcido. $\mathrm{Se}$, tanto os encarregados de analisar a causa, como a parte ex-adversa entregassem tempestivamente a prestação jurisdicional seria a querela resolvida em um tempo bem menor, o que beneficiaria tanto o vencedor, como o judiciário brasileiro.

No entanto, não é o que se observa. O que se tem são processos abarrotando fóruns e tribunais, quando estes poderiam ser resolvidos se não fosse dado às partes, pelo próprio judiciário, opção de interpor quantos recursos fossem necessários para atrapalhar a feitura da justiça, pondo em risco a própria garantia do contraditório e da ampla defesa.

"A demora no processo representa a falibilidade do direito na proteção das situações concretas que sofrem deformações com o decurso do tempo" (GUERRA, 2008, on line) não impingindo uma celeridade real ao processo, em virtude da demora na solução de uma controvérsia muitas vezes simples e de fácil solução.

Nesse passo, o bem mais atacado pela demora na prestação da tutela jurisdicional, não é tão somente o povo, mas intimamente a dignidade da pessoa humana, enquanto corolário de defesa de todo ser humano. Portanto, a parca efetividade da justiça agride sobremaneira a dignidade do ser humano em todos os seus níveis, não deixando de ser um abuso de direito, a pessoa passar anos sem ver seus direitos respeitados e intimamente tendo sua dignidade abalada e, principalmente, atingida de forma cruel e desumana.

Algo que tem sido constante nos tribunais do país é a não observância de todos os direitos inerentes a qualidade de ser humano.

Com a necessidade de uma ordem jurídica igualitária, sentiu-se a obrigatoriedade de impedir que certos atos atrapalhassem ainda mais a entrega da satisfação pretendida. Portanto, o judiciário brasileiro, ao fazer uso da indenização por assédio processual, para proporcionar o deslinde da questão, colocou em pauta um assunto que vinha incomodando diversos ramos da sociedade. 
Passou-se a analisar a situação sob a ótica do ser humano, do respeito à sua dignidade e de se conseguir a satisfação das necessidades do empregado que nunca conseguia usufruir de suas regalias.

Desse modo, colocando dentro do ordenamento jurídico, do processo em si, uma garantia ampla de se resolver o processo dentro de um prazo razoável, ela não poderia ser respeitada, quando se convivia dentro desse mesmo ordenamento com situações que deixavam margem para que se fizesse um uso errado do processo.

A condenação em assédio processual trouxe à baila, uma discussão muito antiga, sobre os meios que possibilitariam à justiça encontrar o caminho para a solução razoável e rápida de um processo, e, no tocante à necessidade primeira do ser humano, de se ver respeitado, uma forma de trazer uma satisfação pessoal.

Portanto, aceita pela jurisprudência como uma forma eficaz de resolver uma lide, o assédio processual, foi transformado em meio inequívoco a que se garanta uma prestação judicial eficiente, e se evite que uma parte se valha de meios inescrupulosos para se ver livre de pagar a sua obrigação tempestivamente e satisfatoriamente.

O tão temerário assédio deve ser imposto como um meio eficaz de resolução de controvérsias. Da forma como foi utilizado pela magistrada na condenação de uma grande instituição financeira a pagar indenização por assédio processual, quando esta estava usando o processo para mitigar as esperanças da parte vencedora.

Deve, principalmente, ser utilizado pelos magistrados, para condenarem maus litigantes, por usarem o meio hábil de resolução de conflitos para causar humilhação e descrença, de forma temerária e desrespeitosa.

\section{CONSIDERAÇÕes FINAIS}

Dessa forma, o processo do trabalho, utilizando-se desse instituto e o explorando ao máximo, tem condições efetivas de prestar a tutela jurisdicional à população, evitando-se que o estado e os próprios cidadãos que o compõem não se prejudiquem pela demora excessiva na resolução de uma lide e pelo mal uso dos institutos postos à disposição para atrasa-la ainda mais.

Imprescindível o enfoque desse tipo de instituto sobre a seara da dignidade humana, defendendo-se uma efetiva proteção a todos os seres humanos. Ora, o que se pode esperar de um país onde o processo demora anos para ser resolvido senão que ele está infringindo a dignidade humana, impedindo que essa pessoa tenha seus direitos respeitados.

Fundamental, então, que o próprio Judiciário, por meio de seus magistrados comece esse caminho de punições aos maus litigantes para que, em face de uma pressão, eles não se sintam à vontade para atrapalhar o processo, e sim, por mais que percam a causa, queiram vê-la resolvida, permitindo-se que o vencedor da lide possa, finalmente, gozar de seus direitos. 


\section{REFERÊNCIAS}

BASTOS, Antonio Adonias Aguiar. O direito fundamental à razoável duração do processo e a reforma do judiciário: uma desmi(s)tificação. Conpedi, Bahia, jun., 2008. Disponível em: <http://www.conpedi.org/manaus/arquivos/Anais/ Antonio\%20Adonias\%20Aguiar\%20Bastos_Efetividades\%20e\%20Garantias\%20 do\%20Processo.pdf>. Acesso em: 14 maio 2009.

BRASIL. Constituição (1988). Constituição da República Federativa do Brasil, Brasília, DF, Senado 1988.

CORDEIRO, Roberto Benavente. Assédio Processual. OAB, São Paulo, out. 2005. Disponível em: $<$ http://www.oabsp.org.br/boletim-informativo/trabalhista/ edicao-03-outubro-de-2005/assedio-processual>. Acesso em: 14 mai. 2009

GUERRA, Gustavo Rabay. O princípio constitucional da razoável duração do processo. Jus Navigandi, Teresina, abr., 2008. Disponível em: <http://jus2.uol. com.br/doutrina/texto.asp?id=11188>. Acesso em: 14 maio 2009.

Organização das Nações Unidas. Convenção Americana sobre os Direitos Humanos. Decreto ${ }^{\circ}$ 678, de 6 de novembro de 1992. Termo de Adesão: 25 set. 1992. Disponível em: <http://www.aids.gov.br/legislacao/vol1_4.htm>. Acesso em: 30 jun. 2008.

. Convenção Européia para a Proteção dos Direitos Humanos. Lei n. ${ }^{\circ}$ 65/78 de 13 de Outubro de 1950. Brasília, DF, Senado, 1978. Disponível em: $<$ http://www.aprendereuropa.pt/document/ConvEuropeiaDH.pdf $>$. Acesso em: 30 jun. 2008.

. Declaração Universal dos Direitos Humanos. Adotada e proclamada pela resolução 217 A (III) da Assembléia Geral das Nações Unidas em 10 de dezembro de 1948. Disponível em: < http://www.aids.gov.br/legislacao/vol1_1. htm>. Acesso em: 30 jun. 2008.

PAROSKI, Mário Vasni. Reflexões sobre a morosidade e o Assédio Processual na Justiça do Trabalho. Revista LTR, Rio de Janeiro, v. 72, n. 9, p. 1112-1118, set. 2006.

RAMOS, Mylena Pereira Ramos. Processo no 02784200406302004. São Paulo, 2004. Autor: Carlos de Abreu. Réu: Banco Itaú S.A.

SILVESTRIN, Gisela Andréia. O dano moral no direito do trabalho. Monografias, Rio Grande do Sul, set/out. 2003. Disponível em: <http//Br.monografias.com/ trabalhos908/o-dano-moral.shtml>. Acesso em: 14 maio 2009.

SOUSA FILHO, Francisco Xavier de. O assédio moral processual na Justiça por arguição de preliminares ilícitas. Jornal Pequeno, Maranhão, mar. 2007. Disponível em: <http://www.jornalpequeno.com.br/2007/3/11/pagina52232.htm>. Acesso em: 14 maio 2009. 


\section{PROCESSUAL HARASSMENT AND LABOUR LAW}

Abstract: The present paper studies how processual harassment can interfere with a working relationship among employees or former employees and their employer. Under this view, it is focused the relation between processual harassment and the labor justice, the reasonable procedural time and the principles under this situation, as predicted by the 1988 Federal Constitution. This paper also introduces the processual harassment concept inside the moral harassment issue.

Keywords: Processual harassment. Fundamental principles. Reasonable processual time. 